\title{
AC 2012-4834: DEVELOPING A PERVASIVE, COLLEGE-WIDE APPROACH TO INTEGRATING ACHIEVEMENT OF GLOBAL COMPETENCE INTO THE CURRICULUM
}

\section{Dr. Gregg Morris Warnick, Brigham Young University}

Gregg M. Warnick is the Director of the Weidman Center for Global Leadership and Associate Teaching Professor of engineering leadership within the Ira A. Fulton College of Engineering and Technology at Brigham Young University (BYU). He works actively with students and faculty to promote and develop increased capabilities in global competence and leadership. His research and teaching interests include globalization, leadership, project management, ethics, and manufacturing processes. Prior to joining BYU, Warnick worked for Becton Dickinson, a Global Medical Technology Company (1995-2006). In this capacity, he worked as a Product Development Engineer, Quality Engineer, Technical Lead, business leader, and Program/Project Manager managing many different global projects. Warnick received his Ph.D. in educational leadership and higher education from the University of Nebraska, Lincoln, with a master's of technology management degree and a B.S. in manufacturing engineering technology, from Brigham Young University. Warnick also is a Professional Associate Instructor for IPS Learning and Stanford University, where he teaches the IPS course Project Management Mastery and the Stanford Advanced Project Management course Managing Without Authority for numerous fortune 500 companies throughout the world, including Cisco, Google, Visa, Barclays, Novo Nordisk, Medtronic, Oracle, Visa, Xilinx, Nationwide Insurance, and Anadarko Petroleum. He is a certified Manufacturing Technologist (Society of Manufacturing Engineers). He is an active member of ASEE.

\section{Dr. Spencer P. Magleby, Brigham Young University}

Spencer Magleby is a professor of mechanical engineering and Associate Dean in the Fulton College of Engineering and Technology at Brigham Young University. He came to BYU in 1989 after working in the aircraft industry developing tools for advanced aircraft design and manufacture. Magleby received his Ph.D. from the University of Wisconsin, where his research centered on design. He has pursued research in design tools and processes, team management, and new mechanism technologies. He teaches design at the graduate and undergraduate level and is interested in educational partnerships with industry and international issues in design. As Associate Dean of undergraduate studies, he has promoted and supported the structuring and expansion of international programs. He is an active member of ASME and ASEE.

\section{Dr. Brent E. Nelson, Brigham Young University}

Brent Nelson is a professor in the Department of Electrical and Computer Engineering at Brigham Young University and Program Head for the Computer Engineering program there. He received his Ph.D. in computer science in 1984 from the University of Utah. He originally developed and serves as Director of the college's Global Leadership Study Abroad in Nanjing, China. His current research interests focus on custom computing architectures using FPGA devices and on fault-tolerant techniques for the use of FPGA devices in harsh environments. He currently serves as Co-director for the U.S. NSF Center for Reconfigurable High Performance Computing (known as CHREC) and as Director of the BYU site within that center. 


\title{
Developing a Pervasive, College-Wide Approach to Integrating Achievement of Global Competence into the Curriculum
}

\begin{abstract}
Like many institutions across the country, we have embarked on the development of experiences and programs related to the objective of achieving global competence in our engineering students. These internationally-oriented activities have been part of a phased plan at the college level to develop a system to achieve global competence within our graduates that is integrated into their curriculum. This paper presents a description of the current state of the college efforts in this area and provides an overview of future directions towards curricular and non-curricular systems. Emphasis is placed on the integration of the system with academic degree programs within the college and resources outside of the college. Reflections on the experiences and learning gained in the development and implementation of the experiences, programs, and hoped-for college-wide system are presented. These reflections are generalized to be lessonslearned that could apply to other institutions working to build their international programs and to achieve integrating global competence into the curriculum.
\end{abstract}

\section{Introduction}

Like many institutions across the country, the Ira A. Fulton College of Engineering and Technology at BYU has embarked on development of experiences and programs related to the objective of achieving global competence in our engineering and technology students. These initiatives, aimed at global competence, have occurred in parallel with efforts to promote technical excellence, ethical behavior in students, innovation, and leadership. The vision of the college is to promote and pursue approaches to developing these competencies that will move us towards a system wherein all students are able to achieve them within the scope of their degree programs. This twin goal of pervasiveness and integration is within sight for leadership. The framework we previously developed for achieving leadership competencies has been a template for the current efforts on achieving global competence ${ }^{1}$. However, there are a number of issues and challenges in this area that are requiring significant thought, planning, and experimenting to overcome.

The goal of having achievement of outcomes be pervasive is simply driven by a desire for all students to achieve competence. While it is clearly valuable for even some students to have opportunities for achievement, it is our goal to have this competence be a part of our institutional culture and image. Of course this latter goal requires broad buy-in from faculty. Later in the paper the transitional strategies we are pursuing to move from selective to pervasive achievement are discussed.

The goal of fully integrating the process of achieving global competence into the curriculum of individual degree programs means that students receive the requisite instruction and experience in courses that "count" towards completion of their engineering degree - either as part of core courses or as electives. We believe integration is necessary to effectively realize pervasiveness and develop institutional culture. While integration may be an end goal, many globally-oriented 
student experiences have rather organic roots that we are now working to bring into degree programs. This is especially true for international study programs where students travel as part of their curriculum. The paper discusses these international study programs and their transitions specifically.

The objective of this paper is to describe the approach and strategy taken by BYU to integrate the achievement of global competence into degree-program curricula across the college, and present the lessons learned. It is the hope of the authors that this discussion might encourage dialog and collaboration on developing institution-wide models. The integration approach builds around some preliminary models that have been developed for examining and promoting integration levels, and program transitions.

The paper first examines the approach of some key institutions to develop global competence. The status and goals of BYU are then reviewed and put into context. We then discuss the transition approach that we are taking to move to the integrated goal state that was presented with some emphasis on international programs. Lessons learned and future directions are then summarized followed by a conclusion.

\section{Approach of Other Universities to Develop Global Competence}

We live and work in a world that is more interconnected and interdependent than ever before. Engineers must now not only develop technical engineering competence, but also additional skills and competencies, including global competence to be successful within a global engineering environment ${ }^{2}$. As we consider the directions taken at BYU, it is helpful to first examine the approaches and progress made by other institutions.

Academic institutions throughout the United States and many parts of the world continue to focus their efforts on how to better prepare their graduates for success within this global context. Global competence, or a strong interest in becoming globally competent, has become a clear differentiator in an engineering graduate's ability to obtain employment, to progress in a career, and to remain viable in the future ${ }^{3}$.

One of the challenges facing engineering programs is how to prepare engineering graduates to contribute within the context of a global workplace and to incorporate international preparation and the development of global competence into an already content-full and highly-sequenced curriculum $^{4}$. Many engineering and technology programs have incorporated different methods to better prepare their students for success within a global environment. Parkinson summarized in a previous ASEE paper ten different methods to provide international opportunities for students including $^{5}:$ 1) dual degree - students obtain two degrees, with one from the home university and the other at an abroad university, 2) exchange - students are exchanged between partner universities and take courses in the abroad language, 3) extended international field trip, 4) extension - university extension campus in an abroad country, 5) international design/capstone projects, 6) international internship or co-op, 7) mentored travel, 8) partner subcontract - home university contracts for courses to be taught at an abroad university, 9) international project/service based learning, and 10) international research. 
Educational leaders and industry continue to press engineering and technology programs to move forward and better prepare students for leadership roles within a global context. This includes a call for these programs to provide more international elements within the curriculum and to provide more international opportunities ${ }^{6}$.

The University of Rhode Island's International Engineering program provides students an opportunity to major in both engineering and a foreign language. This program includes students spending a semester or more living in a foreign country with an industrial internship or participating in a study abroad program at a partner university. This program typically takes 5 years to complete instead of the usual four due to these additional requirements ${ }^{7}$.

Rensselaer Polytechnic Institute (RPI) implemented the Rensselaer Education Across Cultural Horizons (REACH) program with an initiative to provide all undergraduate students with an international experience. This program was initially launched in 2009 and has evolved from an exchange program ${ }^{8}$ for engineering students to include any type of international opportunity. All students are encouraged and expected to take advantage of the many international offerings, including study abroad and exchange opportunities in more than 15 different countries as part of their undergraduate experience. Opportunities also include short-term and faculty led international programs and other international experiences, including internships and service learning ${ }^{9}$.

Purdue University established the Global Engineering Alliance for Research and Education (GEARE) program in partnership with other universities (Shanghai Jiao Tong University China; Universität Karlsruhe - Germany, Indian Institute of Technology Bombay - India; and the Instituto Technological De Estudios Superiores De Monterrey - Mexico) and leading global companies to educate students to be global engineers and global citizens. This program includes five aspects including: 1) language and orientation work 2) a domestic engineering professional experience with a global component, 3) an international professional posting, 4) a semester abroad taking engineering coursework, and 5) one or two semesters of global design work on projects where the diversity of cross-cultural values affect project decisions ${ }^{10}$.

Georgia Tech implemented an integrated approach to develop student global competence as part of their International Plan. The program requires students to engage in at least 26 weeks of international experience that is related to their discipline. In addition, students take international coursework including international relations, global economy, and one course that provides familiarity with an area of the world or a country that allows them to make systematic comparisons with their own society and culture. Students are also required to develop second language proficiency equivalent to at least the second year of study demonstrated through a proficiency exam. In addition, each student's capstone design experience must meet certain international requirements and it is preferable that the project include working with students from a foreign university ${ }^{11}$.

What seems apparent is that a number of university engineering and technology programs continue to focus on improving global competence among their students. Study abroad programs continue to be the most prevalent method to provide global educational experiences for engineering students ${ }^{12,13}$. While study abroad programs are positive experiences for students, 
some research indicates brief cultural injections are not sufficient to directly lead to one becoming globally competent ${ }^{14}$. However, these experiences provide a positive platform for engineering programs that lead to the development of more integrated experiences which supplement or enhance traditional study abroad.

As can be seen, much of what is occurring is an add-on approach made up of short programs including summer programs, minors and certificates. Initial development of student international opportunities is generally additive in nature and not integrated into existing curricula coursework. Generally, this includes additional international experiences and/or coursework which can increase the total number of semesters required for a student to graduate. These international experiences clearly have a positive impact on the students involved and help build their confidence and competence to have an impact in the global engineering workplace. However, these programs are often expensive and have other constraints that make it difficult for all students to be involved. Estimates indicate that less than $20 \%$ of engineering students participate in international experiences ${ }^{15}$ and given this relatively low percentage, it is anticipated that a more comprehensive, efficient, and integrated approach is needed to develop global competence that is pervasive among engineering and technology students.

Some universities have moved towards a more integrated curricular approach. However, many retain additive aspects which include additional credit requirements where students typically take additional courses and participate in different international experiences to meet graduation requirements. Pervasiveness is likely to be achieved as colleges and universities take an integrated approach to focus on their own curricula to make global competency an essential and efficient part of a student's education ${ }^{16,17}$. Incorporating global competence within engineering and technology programs will require a review and modification of existing curricula to make sure it is comprehensive, coherent, efficient, and accessible to all students ${ }^{18}$.

\section{BYU Status and Goals}

The BYU College of Engineering and Technology has about 3,400 students in a variety of engineering and technology programs. Over the last 6 years, the college has encouraged and asked the departments to promote the achievement of student competencies in five areas:
1. Technical Excellence
2. Character/Ethics
3. Innovation
4. Leadership
5. Global Competence

Technical excellence is the foundation for all degree programs and is promoted in traditional ways. Development of character has been promoted throughout the curriculum and is an integral part of the BYU experience. Innovation has a variety of facets and has been promoted at college, department, and program levels through curricular and extra-curricular means. The innovation area is still maturing and a strong model for implementation has not yet been developed. 
Development of leadership competencies has proceeded with a structured model or framework that was designed to be integrated from the beginning. The framework is based on a set of leadership learning outcomes ${ }^{1}$ that are pursued at each student level and has served as a guide for implementation of global competencies:

- Freshmen level - Students are introduced to the importance of cultivating leadership capabilities as part of their educational pursuit. This is accomplished as part of a leadership seminar where freshmen students are taught about the importance of leadership and its importance within their career, learn about the college leadership model including outcomes as part of their development process, and are encouraged to get involved in activities such as clubs, competition teams, extracurricular activities, and service that will help develop additional competencies.

- Sophomore level - All students are required to take a college course entitled "Foundations of Global Leadership" (this course fulfills general education requirements) that addresses the basic principles of leadership, moral/ethical behavior, and global competence. This course has a common syllabus and is taught by faculty across the college. The primary focus is for students to learn and begin to practice leadership within a team and project environment.

- Junior and senior levels - Programs are tasked with providing instruction and experiences that will achieve required leadership outcomes. Students are provided opportunities to gain practical experience and to lead through class assignments, projects, and team-based experiences. With this approach in place, all students will have the chance to achieve leadership competencies without requiring additional time to graduate.

The leadership approach has served as a basic model for achieving global competence among students but there are two main differences that make this challenging. First, the lack of general consensus on what global competencies should or could be pursued within the college. Second the lack of sustainable models to achieve global competence which do not involve inordinate resources.

Two primary thrusts were initiated in the development of a global competence approach: (1) creation of a set of competencies including levels of the competencies, and (2) promotion of the growth of technically-oriented international programs and experiences. Development of competencies has proceeded on a number of fronts and has resulted in a set of publications ${ }^{2,14,19}$ and internal documents. A later paper will more fully address competencies and their relationships to various course and international programs

A variety of international programs have emerged during the period that the college was promoting and guiding their formation. The size and diversity of these programs create both challenges and opportunities for college-wide initiatives, especially those that are resource intensive such as international programs. We have experimented with many different formats over the years to improve achievement of competencies and be efficient in the use of resources. Efforts have included international capstone projects, humanitarian/service learning projects, study abroad experiences at foreign universities, faculty mentored travel, international research, 
faculty sabbaticals at foreign universities, and global virtual teaming in projects such as the Partners for the Advancement of Collaborative Engineering Education (PACE) programs ${ }^{5}$. These international programs have grown and matured to the point that by the end of 2011 approximately 25\% of BYU engineering students participated in an international learning opportunity.

Figure 1, illustrates the end goal of the college to have a college-wide integrated approach to achieve global competence. Success lies in having a system that is integrated within the curriculum, pervasive among students \& faculty, efficient, outcome driven, sustainable, and provides diverse opportunities.

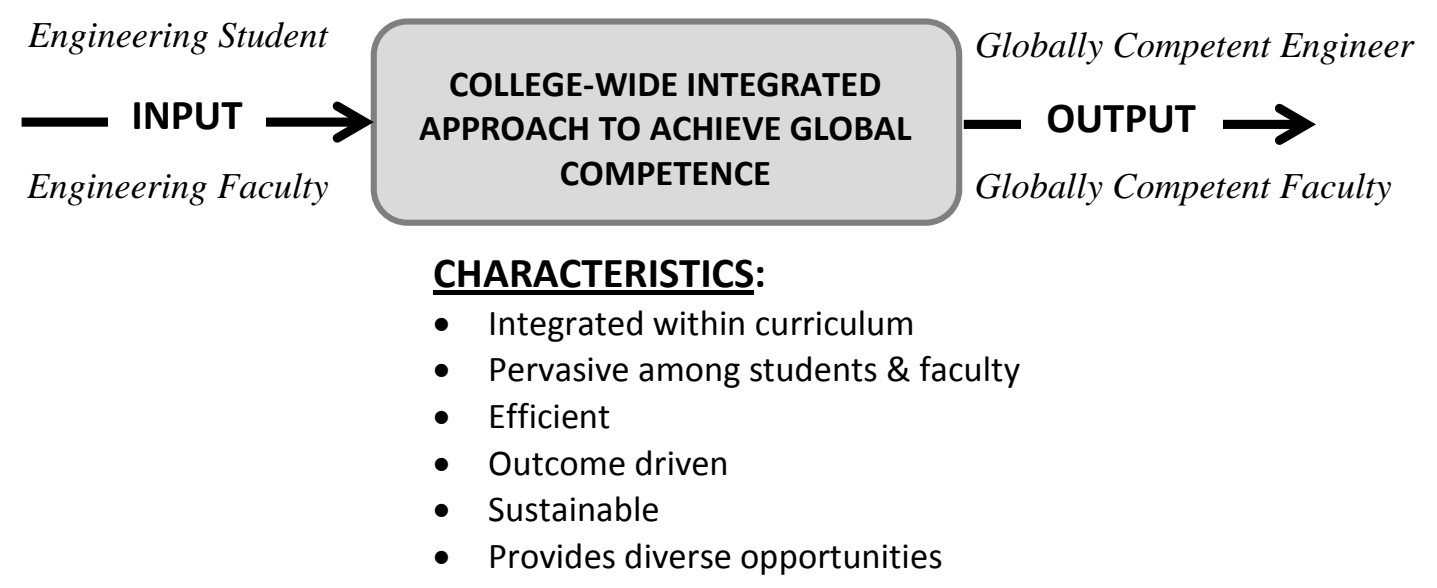

Figure 1. College-Wide Integrated Approach to Achieve Global Competence

As we have moved ahead in the development of approaches for achieving global competence, it has become clear that the development and implementation of international programs are unique in the way that they have evolved and in the challenges they present to integration within the various curricula of the college.

\section{Transition}

We concluded early in the process that a key component of creating a college-wide system would be the development of a broad set of international experiences with enough variety to meet the needs of the students in all the college's programs. Recognizing that the creation of such a set of programs would be a long-term effort, we began, in approximately 2005, to encourage faculty to propose and begin development of international programs. There were two key considerations that guided this work.

First, we believed that the establishment of successful programs would initially require the efforts of faculty who were passionate about some facet of global competence. During the initial establishment phase, we felt it more important to liberally support the efforts of these faculty members rather than make strong efforts to standardize the developing programs in a top-down manner. What was our reasoning in this regard? Although the goal was the development of a rich set of high-quality programs, we recognized that a bottom-up approach was the best way to proceed - it would allow for experimentation and would develop programs ultimately most 
applicable to the needs of the students, faculty and college programs. In the process we recognized the possibility that some proposed programs might fail or require significant modification to be successful and sustainable.

The second consideration which guided our development process was a recognition that once individual programs had successfully demonstrated that they did meet a need and could be sustainable, there would be a need to introduce standardization to ensure that the programs supported our educational outcomes, were well integrated into program requirements, had proper oversight, had sufficient ownership and buy-in at the department level, and were directed by a cadre of trained faculty on a rotating basis. We felt that all of this would be required so that the programs could move beyond being the personal project and domain of a single passionate faculty member and become integrated into our college programs.

We thus believe a natural progression for program maturation should and will occur as shown in Table 1. The key dimensions we have identified for programs include: ownership, participation, curriculum linkage, director status, and program focus.

Table 1: Progression Model for Integrating International Programs into an Engineering Curriculum

\begin{tabular}{|l|c|c|c|}
\cline { 2 - 4 } \multicolumn{1}{c|}{} & \multicolumn{3}{c|}{ Engineering Curriculum Integration Level } \\
\hline $\begin{array}{l}\text { Program } \\
\text { Dimensions }\end{array}$ & University & Medium & High \\
\hline \hline Ownership & Open to all students & $\begin{array}{c}\text { Filtered by major and } \\
\text { class standing }\end{array}$ & $\begin{array}{c}\text { Only students with program- } \\
\text { specific pre-requisites }\end{array}$ \\
\hline Participation & $\begin{array}{c}\text { No formal } \\
\text { relationship }\end{array}$ & $\begin{array}{c}\text { Valid elective credit } \\
\text { for degree }\end{array}$ & $\begin{array}{c}\text { Fulfills one or more program } \\
\text { requirements }\end{array}$ \\
\hline $\begin{array}{l}\text { Lurriculum } \\
\text { Dinkage }\end{array}$ & $\begin{array}{c}\text { Passionate people } \\
\text { pushing the system }\end{array}$ & $\begin{array}{c}\text { Passionate people } \\
\text { that receive teaching } \\
\text { credit }\end{array}$ & $\begin{array}{c}\text { Qualified faculty rotated } \\
\text { through director position }\end{array}$ \\
\hline $\begin{array}{l}\text { Program } \\
\text { Focus }\end{array}$ & $\begin{array}{c}\text { Focus on location } \\
\text { and student } \\
\text { experience }\end{array}$ & $\begin{array}{c}\text { Focus on student } \\
\text { learning }\end{array}$ & $\begin{array}{c}\text { Focus on achieving program } \\
\text { outcomes }\end{array}$ \\
\hline
\end{tabular}

As an example, a typical international experience might begin under the direction of a single faculty member with an interest and expertise in a geographical area (such as Asia). The program would initially be taught under a flex course title (a re-usable generic course listing). In this early stage, individual degree programs may not recognize the experience as fulfilling any specific degree requirements. The goal, over time, is to mature the program and have it move from the leftmost (low curriculum integration) column in Table 1 to the rightmost (high curriculum integration). 
In terms of Ownership, most programs initially relied heavily on the services of the International Study Program office within the David M. Kennedy Center at Brigham Young University. This provides a significant safety net to a new program director in terms of providing a program framework with baseline policies for running the program. It also allows the director to rely on a collection of services, such as handling registration and finances. As programs mature they become more specific to the college and ultimately to department and program needs. In the process, they come to require less help from the university International Studies office as college and department personnel take more and more responsibility for their operation, to the extent appropriate given the institution's constraints.

The Participation and Curriculum Linkage rows in Table 1 are closely related. Initial participation in many programs may be open to all students in good standing, but as programs mature and become more tightly integrated with the curriculum, the selection process and prerequisites for programs become more selective, better allowing programs to satisfy specific program requirements. Ultimately this leads to programs integrated within existing curriculum that are specific to department graduation requirements.

Similarly, the Director Status and Program Focus rows in Table 1 are closely related. In our experience, a typical program is initially proposed by a passionate faculty member with specific interests, both geographic and topical. However, such a program is not sustainable due to director burn out and department resistance. That is, departments may be reluctant initially to spend resources on something which may be considered outside the department's mainstream educational programs. In the medium stage of curriculum integration (once a program has proven itself at some level), our experience is that departments recognize the value of the program and directors then begin to be rewarded for their efforts (in terms of credit at evaluation time). In addition, the focus begins to shift away from the location and experience aspects of the program and toward specific student learning activities which may be satisfied in any of a number of ways and any number of locales. Finally, a truly mature program will be supported by a cadre of qualified faculty who rotate through the director position as a part of their regular assignments, something that is not really feasible before the program is fully integrated into the departments' programs and is recognized as meeting a set of specific curriculum-level outcomes.

\section{Lessons Learned and Future Directions}

The focus of this paper is on developing an integrated as opposed to add-on approach to developing global competence among all our students. This is reflected in the use of the terms "pervasive”, “college-wide”, and "integrated” in the title of the paper. However, the international programs just described in the previous section are add-on programs, meaning that our expectation is that only a self-selecting subset of our students will participate in them due to cost reasons.

Thus, why were they described at the level of detail provided? There are a number of reasons. First, we believe strongly that a key part to developing a pervasive and integrated approach to developing global competence within our college is to effect a culture change and raise the students' awareness of global considerations in their pursuit of engineering degrees. Having a set of flagship international experiences contributes much to that culture change. 
The second reason for discussing our international programs is that there is much we can learn from them about how best to go about integrating our global competence components for all students into the college's academic programs. Thus, the focus in the previous section was not on the specific program details specifically. Rather, it was on the evolutionary process we have used to take international programs and experiences (which were initially viewed by many faculty and administrators as being outside the mainstream) and integrate them into the core of college's academic programs.

The first lesson we have learned, or rather confirmed, is that an integrated approach is crucial to sustainability. This can be illustrated by contrasting two programs - one operating in the right column of Table 1 and one operating in the middle to left columns of Table 1.

One of our international study abroad programs (Megastructures) is closely tied to a senior level structural design course and fulfills a specific degree requirement for our Civil Engineering degree. The shaded areas in Table 2, highlights the integration of this course within the curriculum. Initial intuition might suggest that a single senior level course does not provide a large enough pool of candidate students to draw from for a relatively expensive multi-week trip to China. However, experience has shown that its tight integration with the senior level course is the draw for students and, as such, our Megastructures study abroad has more applicants each time it is offered than can be supported.

Table 2: Implementation Level of Megastructures (China) Course

\begin{tabular}{|l|c|c|c|}
\cline { 2 - 4 } \multicolumn{1}{c|}{} & \multicolumn{2}{c|}{ Engineering Curriculum Integration Level } \\
\hline $\begin{array}{l}\text { Program } \\
\text { Dimensions }\end{array}$ & University & Medium & High \\
\hline \hline Ownership & College & Department/Program \\
\hline Participation & Open to all students & $\begin{array}{c}\text { Filtered by major and } \\
\text { class standing }\end{array}$ & $\begin{array}{c}\text { Only students with program- } \\
\text { specific pre-requisites }\end{array}$ \\
\hline $\begin{array}{l}\text { Curriculum } \\
\text { Linkage }\end{array}$ & $\begin{array}{c}\text { No formal } \\
\text { relationship }\end{array}$ & $\begin{array}{c}\text { Valid elective credit } \\
\text { for degree }\end{array}$ & $\begin{array}{c}\text { Fulfills one or more program } \\
\text { requirements }\end{array}$ \\
\hline $\begin{array}{l}\text { Director } \\
\text { Status }\end{array}$ & $\begin{array}{c}\text { Passionate people } \\
\text { pushing the system }\end{array}$ & $\begin{array}{c}\text { Passionate people } \\
\text { that receive teaching } \\
\text { credit }\end{array}$ & $\begin{array}{c}\text { Qualified faculty rotated } \\
\text { through director position }\end{array}$ \\
\hline $\begin{array}{l}\text { Program } \\
\text { Focus }\end{array}$ & $\begin{array}{c}\text { Focus on location } \\
\text { and student } \\
\text { experience }\end{array}$ & $\begin{array}{c}\text { Focus on student } \\
\text { learning }\end{array}$ & $\begin{array}{c}\text { Focus on achieving program } \\
\text { outcomes }\end{array}$ \\
\hline
\end{tabular}

In contrast, our global leadership study abroad to China is open to all students within the college and has as its focus the study of globalization and international engineering (design and manufacturing). The shaded areas in Table 3, highlights the integration of this course within the curriculum. 
Although not a program specific course, it is accepted by all engineering and technology degree programs within the college as fulfilling a technical elective requirement. This technical elective course is reflected in Table 3 where the "Medium" box has been highlighted in the Curriculum Linkage row. The "Low" box is also highlighted in that same row, reflecting an additional course on Chinese Language and Culture which is also a part of this study abroad. Initial intuition might suggest that this study abroad would be over-subscribed due to the huge pool of possible candidates within the college but enrollments have, in fact, been modest. We generally have more capacity than enrolled students each year. Discussions with students indicate that the looser coupling of the experience with the student's degree requirements is a real consideration that affects their decision to participate and that a tighter coupling would make the program more attractive.

Table 3: Implementation Level of Global Leadership (China) Course

\begin{tabular}{|l|c|c|c|}
\cline { 2 - 4 } \multicolumn{1}{c|}{} & \multicolumn{3}{c|}{ Engineering Curriculum Integration Level } \\
\hline $\begin{array}{l}\text { Program } \\
\text { Dimensions }\end{array}$ & University & Medium & High \\
\hline Ownership & Open to all students & $\begin{array}{c}\text { Filtered by major and } \\
\text { class standing }\end{array}$ & $\begin{array}{c}\text { Only students with program- } \\
\text { specific pre-requisites }\end{array}$ \\
\hline Participation & No formal \\
Linkage & $\begin{array}{c}\text { Valid elective credit } \\
\text { for degree }\end{array}$ & $\begin{array}{c}\text { Fulfills one or more program } \\
\text { requirements }\end{array}$ \\
\hline $\begin{array}{l}\text { Director } \\
\text { Status }\end{array}$ & $\begin{array}{c}\text { Passionate people } \\
\text { pushing the system }\end{array}$ & $\begin{array}{c}\text { Passionate people } \\
\text { that receive teaching } \\
\text { credit }\end{array}$ & $\begin{array}{c}\text { Qualified faculty rotated } \\
\text { through director position }\end{array}$ \\
\hline $\begin{array}{l}\text { Program } \\
\text { Focus }\end{array}$ & $\begin{array}{c}\text { Focus on location } \\
\text { and student } \\
\text { experience }\end{array}$ & $\begin{array}{c}\text { Focus on student } \\
\text { learning }\end{array}$ & $\begin{array}{c}\text { Focus on achieving program } \\
\text { outcomes }\end{array}$ \\
\hline
\end{tabular}

Another lesson we have learned is that ownership is crucial and that having local academic units take ownership of any efforts to add new competencies to programs of study is required. As mentioned above, our college has previous experience integrating leadership content within the curriculum. Our experience with both our study abroad programs as well as our leadership competency efforts has been that it is important to provide a vision for the desired outcomes and then repeatedly articulate that vision, all the while asking/encouraging/persuading the academic units to integrate elements of the outcomes into their degree programs. In our experience, the desired culture shift does occur, even if more slowly than some would want, as long as the academic units have final responsibility for integrating the new outcomes into programs of study and a consistent message and vision is provided by the college leadership.

A final lesson learned is that the culture shift needs to take place among not only the students but also among faculty. The evolutionary process described above initially relies on a few passionate faculty members who pursue global competency building activities for students as an add-on to their responsibilities. Positive initial results have led to chairs and other administrators 
more fully supporting these programs, opening the way to their being integrated into the academic programs.

Our institution has clearly not arrived in terms of our goal to develop a pervasive, college-wide program to develop global competencies among our students. However, our experiences thus far are encouraging. As one example, one of our academic units has very much embraced global competence as an important part of their program and taken ownership of a number of initiatives to develop global competence among their students. As a result, over half of their recent graduates have had a significant international experience upon graduation. Other units are farther behind but we do see positive movement along the evolutionary path outlined above in all our departments.

\section{Conclusion}

We live in a rapidly changing world and these changes necessitate the need to better prepare our engineering faculty and students to meet the demands of this changing environment. We have the opportunity as engineering and technology educators to improve the preparation of our graduates to work in and be leaders in a global engineering context. Many engineering and technology programs in higher education are actively involved in efforts to develop global competence in their students and faculty. However, a more pervasive and integrated curriculum approach will help ensure that all students and faculty have an opportunity to develop globally competent skills that will better prepare them for success in the future.

\section{Bibliography}

${ }^{1}$ Hawks, V., Harb, J., Parkinson, A., \& Magleby, S. A college-wide program for teaching leadership: Framework, model, and outcomes. Proceedings of 2009 ASEE Annual Conference \& Exposition. AC 2009-1287, Austin, TX: ASEE.

${ }^{2}$ Warnick, G. M., Global competence: Determination of its importance for engineers working in a global environment. PhD diss., Department of Educational Administration, University of Nebraska - Lincoln, 2010. Accessed 12/13/2011 from http://digitalcommons.unl.edu/cehsedaddiss/35/.

${ }^{3}$ Allan, M., \& Chisholm, C. U. (2008). The development of competencies for engineers within a global context. EE2008 (pp. 1-12). Loughborough: Higher Education Academy Engineering Subject Centre and the UK Centre for Materials Education.

${ }^{4}$ Lohmann, J. R., Rollins, H. A., \& Hoey, J. J. (2006). Defining, developing and assessing global competence in engineers. European Journal of Engineering Education, 31 (1), 119-131.

${ }^{5}$ Warnick, G.M., S.P. Magleby, R.H. Todd, A. Parkinson, Globalization: A New Frontier for Capstone Courses, Proceedings of 2008 ASEE Annual Conference \& Exposition. AC 2008-1230, Pittsburg, PA: ASEE.

${ }^{6}$ Todd, R.H., S.P. Magleby, and A.R. Parkinson, "Experiences and Observations in Introducing Students to Design and Manufacturing Globalization”, Journal of Manufacturing Systems, Volume 24, Number 3, p. 162-170.

${ }^{7}$ Blumenthal, P., \& Grothus, U. (2008). Developing global competence in engineering students: U.S. and German approaches. Online Journal for Global Engineering Education, 3 (2), 1-12.

${ }^{8}$ Renganathan, V., Gerhardt, L., Blumenthal, P., \& Greenwood, A. (2008). Incorporating global perspectives in U.S. engineering education. Proceedings of the 2008 ASEE Annual Conference \& Exposition. AC 2008-2603. Pittsburgh, PA: ASEE.

${ }^{9}$ Hajela, P. Rensselaer Education Across Cultural Horizons, Office of International Programs, Rensselaer Polytechnic Institute. Accessed 1/10/2012 from http://undergrad.rpi.edu/update.do 
${ }^{10}$ Hirleman, E. D., Eckard, A. G., \& Atkinson, D. L. (2007). The three axes of engineering education. Proceedings of the International Conference on Engineering Education. Coimbra, Portugal.

${ }^{11}$ Georgia Tech. (n.d.). International Plan. Accessed 12/12/2011 from http://www.internationalplan.gatech.edu/.

${ }^{12}$ Qamhiyah, A.Z., "Internationalization of the Undergraduate Engineering Program, Part 1: The Need”, International Journal of Engineering Education, Vol. 21, No. 1, pp. 158-165, 2005.

${ }^{13}$ Parkinson, A.P., Engineering Study Abroad Programs: Formats, Challenges, Best Practice, Proceedings of the ASEE 114th Annual Conference and Exposition, Honolulu, Hawaii, June 24-27, 2007.

${ }^{14}$ Hunter, B., White, G.P., Godbey, G., What does it mean to be globally competent? Journal of Studies in International Education, Vol. 10, No. 3, 267-285 (2006)

${ }^{15}$ Mariasingam, M., Smith, T., \& Courter, S. (2008). Internationalization of engineering education. Proceedings of the ASEE Annual Conference \& Exposition. AC 2008-1144. Pittsburgh, PA: ASEE.

${ }^{16}$ Downey, G. L., \& Lucena, J. C. (2007). Globalization, diversity, leadership, and problem definition in engineering education. 1st International Conference on Research in Engineering Education. ISBN: 0-87823-193-5. Honolulu, HI: ASEE.

${ }^{17}$ Downey, G.L., Lucena, J.C., Moskal, B.M., Bigley, T., Hays, C., Jesiek, B.K., Kelly, L., Miller, J., Ruff, S., Lehr, J.L., Nichols-Belo, A., "The Globally Competent Engineer: Working Effectively with People Who Define Problems Differently”, Journal of Engineering Education, 95 (3), 2006.

${ }^{18}$ Brustein, W. I. (2007). Paths to global competence: Preparing American college students to meet the world. Retrieved from http://www.iienetwork.org/page/84657/.

${ }^{19}$ Parkinson, A. (2009). The rationale for developing global competence. Online Journal for Global Engineering Education 4: 1-15. 